\title{
Design and Simulation Studies on Linearised MEMS Capacitive Accelerometers with different Beam Springs
}

\author{
M. Narayanaswamy ${ }^{1 *}$, R. Joseph Daniel ${ }^{2}$, E. Christy Sujeetha Mary ${ }^{3}$ \\ Associate Professor, Dept. of Electronics and Instrumentation Engg., \\ FEAT, Annamalai University, Annamalainagar, India ${ }^{1}$ \\ Professor, Dept. of Electronics and Instrumentation Engg., FEAT, Annamalai University, Annamalainagar, India ${ }^{2}$ \\ M.E (Micro Electronics and MEMS), Dept. of Electronics and Instrumentation Engg., FEAT, Annamalai University, \\ Annamalainagar, India ${ }^{3}$ \\ *Corresponding author e-mail: mns_au@yahoo.co.in
}

\begin{abstract}
Capacitive accelerometers based on change in air gap measurement often experiences non-linearity. In order to overcome this drawback, the overlapping area of the device is changed which produces linear output. In this paper, four different types of beam springs (viz. Half-folded spring, Meander spring, Serpentine spring and Zig-Zag spring) were introduced in the capacitive accelerometer structure. All the springs are subjected to different accelerations and linear outputs are obtained. The cross-axis performance of the four springs is compared. Among the four springs, Halffolded spring and Serpentine spring provide low cross-axis sensitivity. The structures are designed, analysed and simulated using IntelliSuite software.
\end{abstract}

Keywords: Capacitive accelerometer; Overlapping area; Beam Springs; Cross-axis sensitivity; Intellimask.

\section{INTRODUCTION}

In general capacitive measurements are inherently non-linear. By changing the overlapping area between the fixed and moving fingers, linear capacitance measurements can be obtained. Cross-axis sensitivity is estimated using half-folded spring beam structure [1]. Micro Electro Mechanical Systems (MEMS) which involves the integration of both mechanical and electronic components on a single chip. Some of the MEMS devices are Accelerometers, Gyroscopes, Pressure sensors etc. where numerous research studies have been carried out. In which, accelerometers plays a vital role in healthcare, vehicle safety system etc. [2]. They are cheaper in cost because of their smaller size compared to the conventional design of the accelerometer, it weighs lesser, function more efficiently [3]. The selection of type and model of the MEMS accelerometer is important before the design parameter can be determined [4]. There are several sensing mechanisms for detecting acceleration. However, capacitive type sensing mechanism has more advantages and hence it is popular method of sensing acceleration. The advantages of capacitive accelerometers are such as high sensitivity, high reliability, low temperature dependence and low power consumption [5].The capacitive type sensing accelerometer consists of a proof mass anchored to a fixed beam by one or more springs. Capacitive sensors are generally used for linear rather than angular proximity measurement. Either the dielectric or one of the capacitor plates is movable for angular or linear displacement measurement [2]. For sensing acceleration, capacitive accelerometers commonly use distance-changed capacitors. These accelerometers exhibit non-linearity. To make them linear, areachanged capacitance is proposed [6].

In this investigation, four different types of beam springs are proposed to the structure and their cross-axis sensitivity are compared. The design, fabrication and simulations of the capacitive accelerometer are done by Intellimask 3D Builder and Thermo Electro Mechanical analysis. Also, this work is to identify the spring type which results in best cross-axis sensitivity.

\section{PROPOSED DESIGN OF CAPACITIVE ACCELEROMETER}

The proposed MEMS capacitive accelerometer design consists of a proof mass suspended by a beam spring structure which provides the greatest flexibility, highest sensitivity and maximum displacement of the proof mass. The structure has six fingers, in that two fingers on the top that are placed at the centre of the proof mass called as movable fingers 


\section{IJIREEICE}

\section{International Journal of Innovative Research in Electrical, Electronics, Instrumentation and Control Engineering}

\section{Vol. 7, Issue 7, July 2019}

shown in Figure 1 and four fingers that are kept fixed at the bottom of the proof mass called as fixed fingers shown in Figure 2. The spring beam holds the proof mass. Two comb-shaped fixed electrodes with their fingers side by side are alternately placed under the mass. An external force is applied to the proof mass through the suspended beam. The proof mass along with the movable fingers moves in the direction of the force applied. The movement of the fingers from its original position changes the overlapping area between the fixed and moving fingers and hence the capacitance changes. Here, the distance between the fixed and moving fingers remains constant.

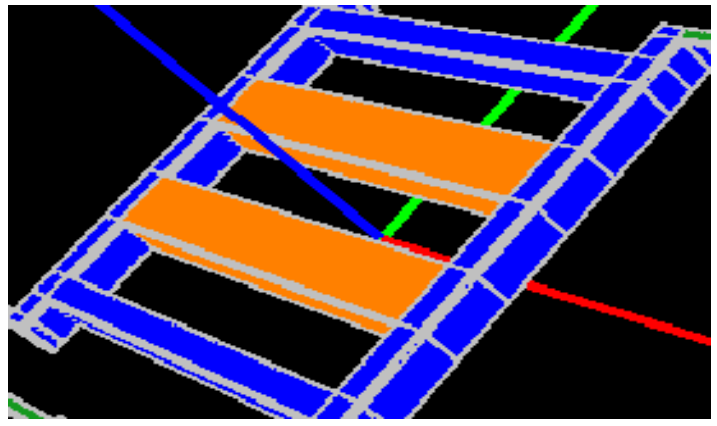

Figure 1. Movable fingers at the Top of the Proof mass.

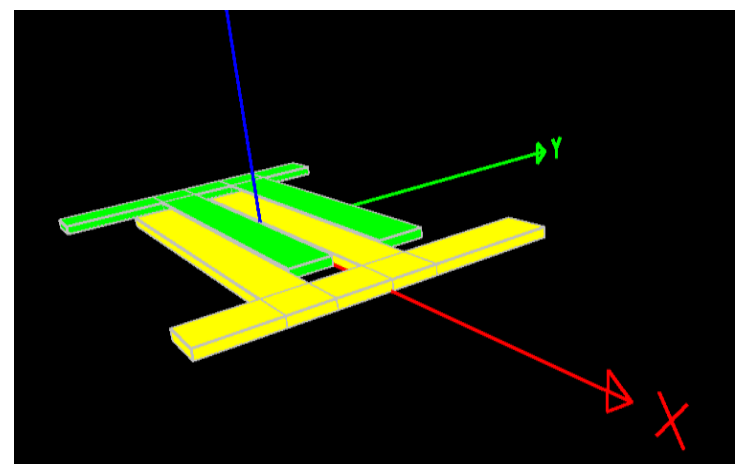

Figure 2. Fixed fingers at the bottom of the Proof mass.

\section{DIFFERENT BEAM SPRINGS}

MEMS capacitive accelerometer requires careful investigation in the suspension system in which different types of springs are proposed. The proposed springs are Half-folded spring, Meander spring, Serpentine spring and Zig-Zag spring as shown in Figures 3-6 respectively and the simulated view of the above said springs are shown in Figures 710.

All the springs are composed of four beams made of Silicon. Half-folded spring is the most convenient way to make a spring structures [5]. A Meander spring consists of two connector beams and two span beams [7]. One end is connected to the proof mass and the other is connected to the anchor.

\begin{tabular}{|c|c|}
\hline Figure 3. Half-folded spring. \\
\hline Figure 5. Serpentine spring.
\end{tabular}




\section{International Journal of Innovative Research in Electrical, Electronics, Instrumentation and Control Engineering}

\section{Vol. 7, Issue 7, July 2019}

The Serpentine spring can be defined by repeated meanders and looks like snake-like pattern of the beam segments. Each meander is of length ' $a$ ', width ' $b$ '. The beam segments that span the meander width are called span beams or spans. The beam segments that connect the spans are called connector beams or connectors. The parameters of the proposed springs are shown in Table 1.

Table 1. Design parameters of the springs.

\begin{tabular}{|l|c|c|c|c|}
\hline \multicolumn{1}{|c|}{ Design parameters } & \multicolumn{3}{|c|}{ Dimensions } \\
\hline Springs & Half-folded & Meander & Serpentine & Zig-Zag \\
\hline Length $x$ width & $1100 \mu \mathrm{m} \times 4 \mu \mathrm{m}$ & $57.6 \mu \mathrm{m} \times 3.2 \mu \mathrm{m}$ & $11.5 \mu \mathrm{m} \times 2.5 \mu \mathrm{m}$ & $50.5 \mu \mathrm{m} \times 3.5 \mu \mathrm{m}$ \\
\hline
\end{tabular}

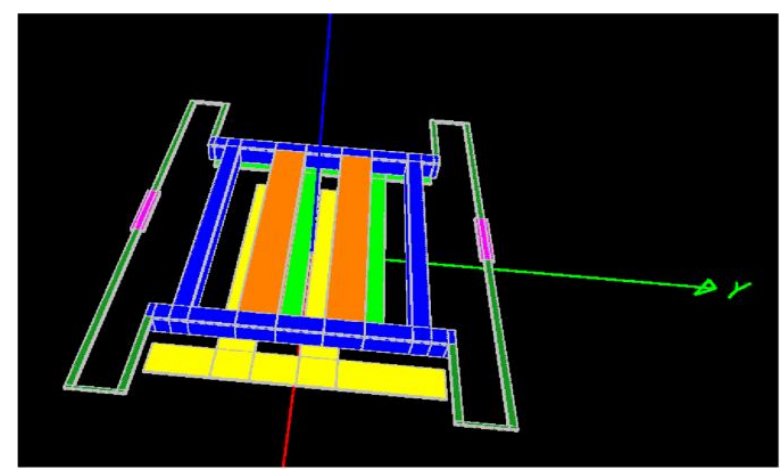

Figure 7. Simulated view of Capacitive accelerometer with Half-folded spring.

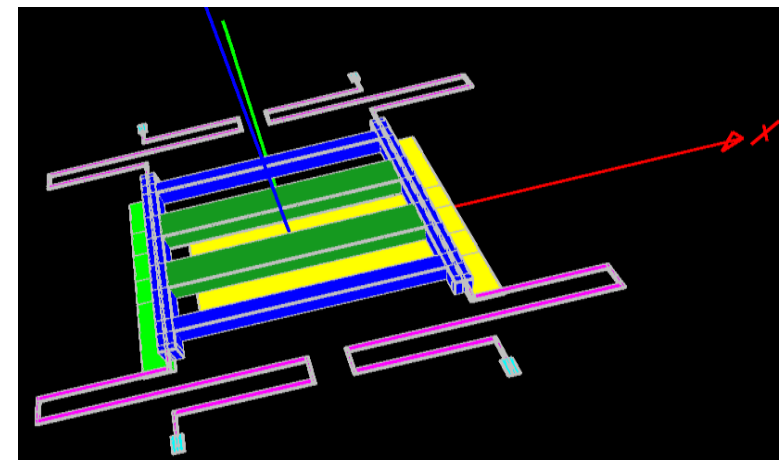

Figure 8. Simulated view of Capacitive accelerometer with Meander spring.

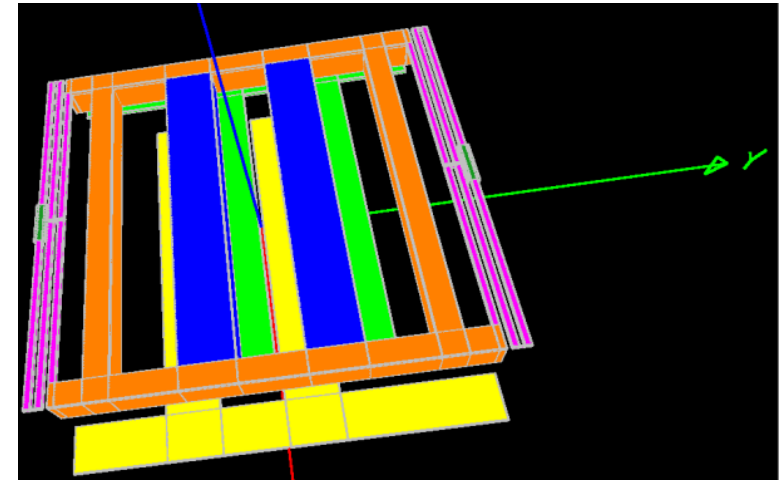

Figure 9. Simulated view of Capacitive accelerometer with Serpentine spring. 


\section{IJIREEICE}

\section{International Journal of Innovative Research in Electrical, Electronics, Instrumentation and Control Engineering}

Vol. 7, Issue 7, July 2019

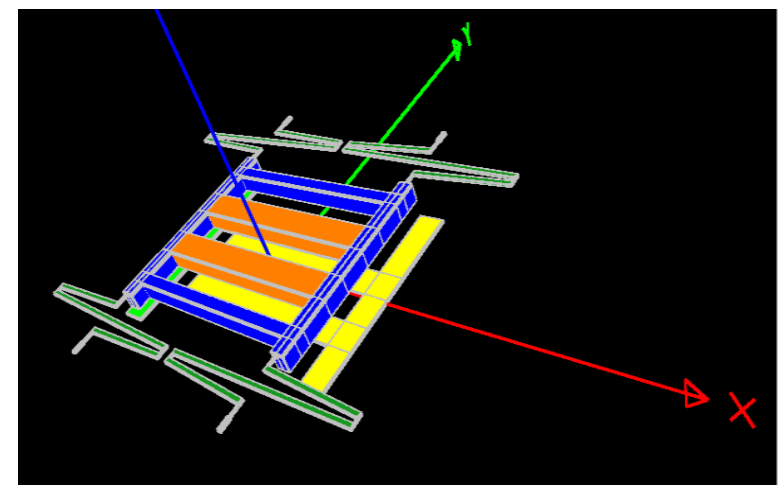

Figure 10. Simulated view of Capacitive accelerometer with Zig-Zag spring.

\subsection{Properties of Silicon}

Single crystal silicon (100) material is selected for accelerometer structure. Silicon is almost an ideal structural material; it has about the same Young's modulus as steel but is as light as aluminium. The melting point of silicon is $1400^{\circ} \mathrm{C}$ and the thermal expansion co-efficient are much less than steel which makes it dimensionally stable even at high temperatures. Electrically conductive silicon with resistivity $0.1 \Omega-\mathrm{cm}$ is selected for the proof-mass [2]. The material properties of silicon used in the research are given in Table 2[14].

Table 2. Material properties of Silicon.

\begin{tabular}{|l|c|}
\hline \multicolumn{1}{|c|}{ Material property } & Silicon \\
\hline $\boldsymbol{\Sigma}_{\mathbf{y}}$ (yield strength) & $7 \times 10^{9} \mathrm{n} / \mathrm{m}^{2}$ \\
\hline $\mathbf{E}$ (Young's modulus) & $170 \times 10^{9} \mathrm{n} / \mathrm{m}^{2}$ \\
\hline $\mathbf{v}$ (Poisson's ratio) & 0.28 \\
\hline $\mathbf{P}$ (density) & $2.3 \mathrm{~g} / \mathrm{cm}^{3}$ \\
\hline
\end{tabular}

\subsection{Analytical Design}

Mathematical equations are used for the calculations of mass, spring stiffness, cross-axis sensitivity and natural frequency.

The displacements of the proof mass along with the movable fingers are in y-direction at various accelerations that ranges from $0-2 \mathrm{~g}$. The displacement of the proof mass for half folded spring can be expressed as [6],

$$
\delta=\frac{\rho S \mathrm{LL}^{3}}{2 \mathrm{~Eb}^{3}} \text { in } \mu \mathrm{m}
$$

where

$\rho$ is the density of the mass in $\mathrm{g} / \mathrm{m}^{3}$

$\mathrm{S}$ is the area of the mass in $\mathrm{m}^{2}$

$a$ is the acceleration in $\mathrm{m} / \mathrm{s}^{2}$

$\mathrm{E}$ is the Young's modulus in $\mathrm{N} / \mathrm{m}^{2}$

$\mathrm{b}$ is the width of the beam in $\mu \mathrm{m}$ and

$\mathrm{L}$ is the length of the beam in $\mu \mathrm{m}$.

\subsection{Spring Stiffness}

Spring stiffness ' $\mathrm{K}_{\mathrm{s}}$ ' depends on the geometry of silicon beam and Young's modulus of the material. The spring constant determines the extent of displacement of the proof mass. The total spring constant of the structure ' $\mathrm{K}$ ' is the sum of the spring constants of the individual spring [8-10]

$\mathrm{K}=4 \mathrm{~K}_{\mathrm{s}}$ 


\section{International Journal of Innovative Research in Electrical, Electronics, Instrumentation and Control Engineering}

Vol. 7, Issue 7, July 2019

$\mathbf{K}_{s}=\left\{\begin{array}{c}\frac{24 E I}{L^{3}} \text { in } \frac{\mathrm{N}}{\mathrm{m}}, \text { for Half }- \text { folded spring } \\ \left(\frac{8 a^{3}+2 b^{3}}{3 E I}+\frac{a b(3 b+15 a)}{3 G J}-\frac{a^{2}\left(\frac{2 a}{E I}+\frac{3 b}{G J}\right)^{2}}{2\left(\frac{a}{E I}+\frac{b}{G J}\right)}-\frac{b^{2}}{2}\left(\frac{a}{G J}+\frac{b}{E I}\right)\right)^{-1}\end{array}\right.$

$\mathbf{G}=\frac{E}{2(1+\vartheta)}$

$\mathrm{J}=\frac{1}{3} t^{3} b\left\{1-\frac{192}{\pi^{5}} \frac{t}{b} \sum_{i=1, o d d}^{\infty} \frac{1}{i^{5}} \tanh \left(\frac{i \pi b}{2 t}\right)\right\}$

where

$\mathbf{J}$ is the torsion constant.

$\mathrm{a}$ is the acceleration in $\mathrm{m} / \mathrm{s}^{2}$.

$\mathrm{b}$ is the width of the beam in $\mu \mathrm{m}$.

$\mathrm{I}$ is the moment of inertia in $\mathrm{kg} \cdot \mathrm{m}^{2}$.

$\mathrm{G}$ is the torsion modulus.

E is the Young's modulus in $\mathrm{N} / \mathrm{m}^{2}$ and

$\mathrm{L}$ is the length of the beam in $\mu \mathrm{m}$.

The specifications for the design parameter of the capacitive accelerometer is shown in Table 3.

Table 3. Specifications of the accelerometer.

\begin{tabular}{|l|c|}
\hline \multicolumn{1}{|c|}{ Parameters } & Values \\
\hline Acceleration range & $0-2 \mathrm{~g}$ \\
\hline Non-linearity & $<5 \%$ \\
\hline Displacement of the proof mass & $10 \mu \mathrm{m}$ \\
\hline
\end{tabular}

Table 4 shows the length, width and thickness of the fixed and moving fingers represented as $\mathbf{l}_{\mathbf{1}}, \mathbf{w}_{\mathbf{1}}, \mathbf{t}_{\mathbf{1}}$ and $\mathbf{l}_{\mathbf{2}}, \mathbf{w}_{\mathbf{2}}, \mathbf{t}_{\mathbf{2}}$ respectively. Area of the proof mass is a, beam length, width and thickness are denoted as $\mathbf{L}, \mathbf{b}, \mathbf{t}$ respectively and $\mathbf{d}$ is the distance between the fixed and moving fingers.

Table 4. Design parameters of the capacitive accelerometer.

\begin{tabular}{|l|c|}
\hline \multicolumn{1}{|c|}{ Design Parameters } & Dimensions \\
\hline Area of the proof mass $(\mathbf{a})$ & $6.56 \times 10^{-8} \mathrm{~m}^{2}$ \\
\hline Number of fingers $(\mathbf{N})$ & 6 \\
\hline Fixed fingers $\left(\mathbf{l}_{\mathbf{1}} \times \mathbf{w}_{\mathbf{1}} \times \mathbf{t}_{\mathbf{1}}\right)$ & $1600 \mu \mathrm{m} \times 22 \mu \mathrm{m} \times 0.3 \mu \mathrm{m}$ \\
\hline Movable fingers $\left(\mathbf{l}_{\mathbf{2}} \times \mathbf{w}_{\mathbf{2}} \times \mathbf{t}_{\mathbf{2}}\right)$ & $1600 \mu \mathrm{m} \times 22 \mu \mathrm{m} \times 3 \mu \mathrm{m}$ \\
\hline Beam $(\mathbf{L} \times \mathbf{b} \times \mathbf{t})$ & $1100 \mu \mathrm{m} \times 4 \mu \mathrm{m} \times 0.3 \mu \mathrm{m}$ \\
\hline Distance between the fingers $(\mathbf{d})$ & $3 \mu \mathrm{m}$ \\
\hline
\end{tabular}

\section{Simulation ANALYSES}

The displacement, change in capacitance, cross-axis sensitivity, voltage analysis and natural frequency were studied from the response of the accelerometer which is subjected to the accelerations from $0-2 \mathrm{~g}$.

\subsection{Displacement Analysis}

The acceleration under the range of $0-2 \mathrm{~g}$ is given to the proof mass in $\mathrm{y}$-direction for all the four spring structures. The displacement of the proof mass in y direction is greater compared to the displacement in $\mathrm{x}$ direction and $\mathrm{z}$ direction for all the beam spring structures and the response thus obtained are shown in Figure 11. 


\section{International Journal of Innovative Research in Electrical, Electronics, Instrumentation and Control Engineering}

Vol. 7, Issue 7, July 2019

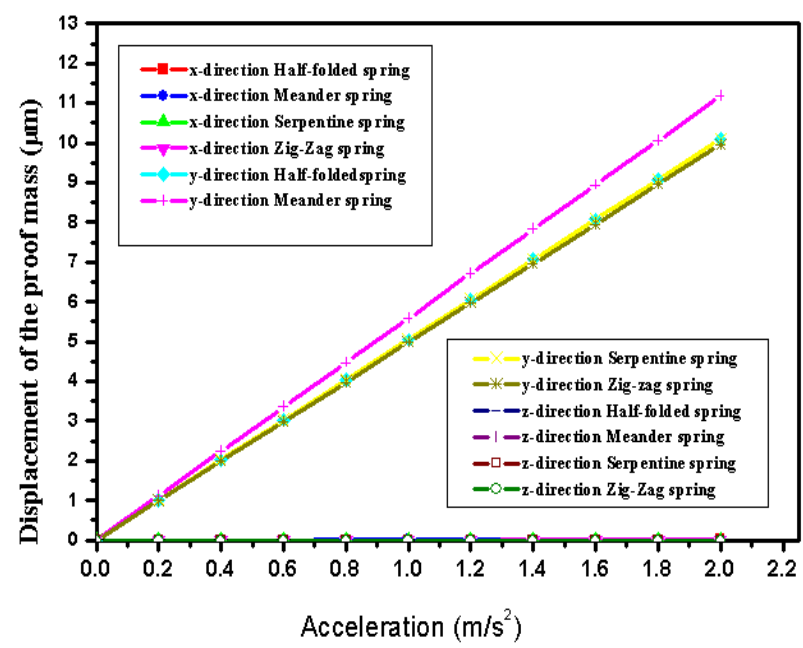

Figure 11. Acceleration Vs Displacement of the beam with various springs.

Further, the displacement has been theoretically evaluated using Equation (1) for different accelerations ranging from 0-2 g. These values are very closely matches with the simulation results shown in Figure 11.

The displacement error can be obtained by using the formula,

error $=\frac{\delta_{\mathrm{T}}-\delta_{\mathrm{S}}}{\delta_{\mathrm{T}}} \times 100$

From the Equation (7), $\boldsymbol{\delta}_{\mathbf{T}}$ is the theoretical displacement of the proof mass and $\boldsymbol{\delta}_{\mathbf{s}}$ is the displacement obtained by simulation.

\subsection{Cross-axis Sensitivity Analysis}

Cross-axis sensitivity is a measure of how much the output is seen on one axis when acceleration is imposed on other axis. From Figure 11, the displacement of the proof mass along $\mathrm{x}$ and $\mathrm{z}$ direction is small compared to the displacement in y direction for the four springs and hence the cross axis sensitivity is estimated in y-axis as shown in Table 5 .

Table 5. Cross-axis sensitivity of the springs in y- direction.

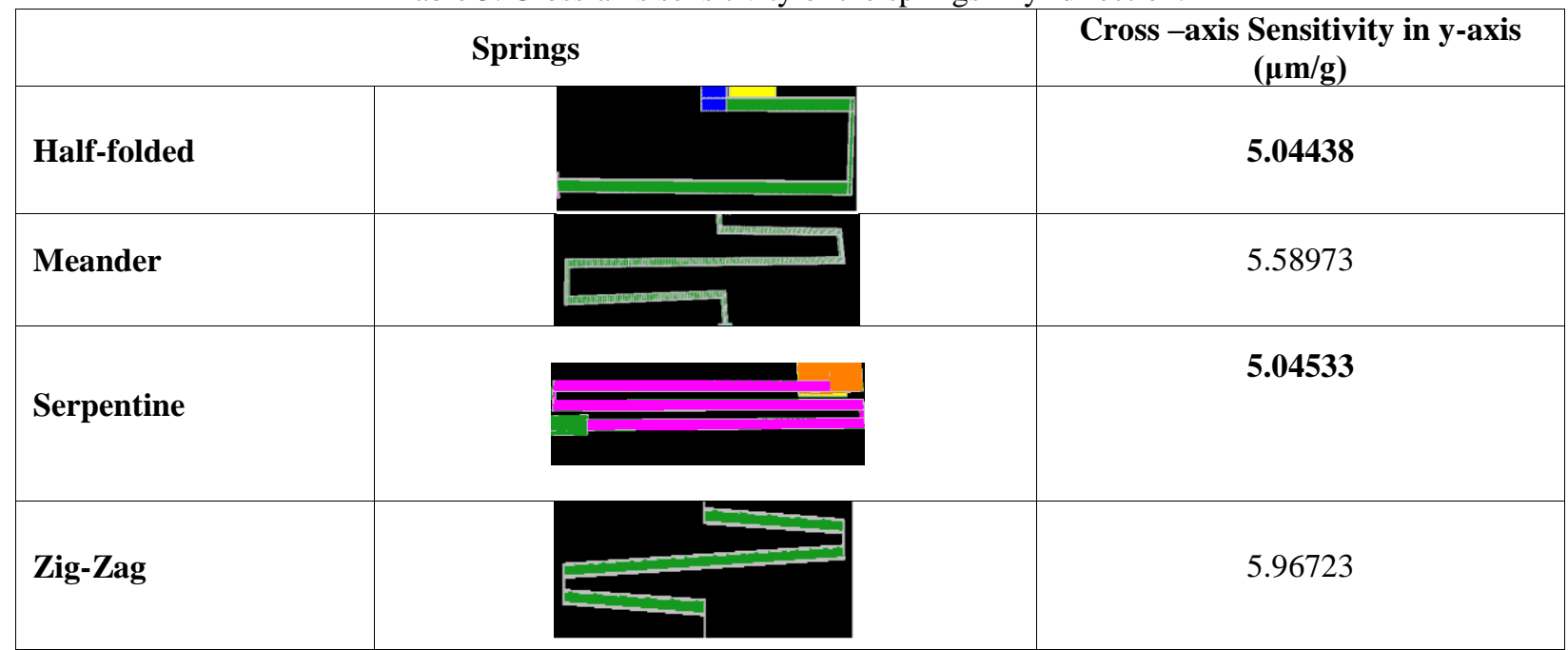

Thus, the accelerometers for all the four springs show excellent cross - axis sensitivity in y- axis [11]. Cross-axis sensitivity can be estimated by using the formula,

\section{Cross-axis sensitivity $=$ max.displacement $/$ gravity, in $\mu \mathrm{m} / \mathrm{g}(8)$}

When comparing all the four spring structures from the Table 5, the cross-axis sensitivity is low in Half-folded spring and Serpentine spring. 


\section{International Journal of Innovative Research in Electrical, Electronics, Instrumentation and Control Engineering}

Vol. 7, Issue 7, July 2019

\subsection{Capacitance Analysis}

When there is no acceleration, the overlapping area between fixed fingers and moving fingers remains no change. The static capacitance can be expressed as [7]

$$
C_{0}=\frac{N \varepsilon_{0} A}{2 d}
$$

When the acceleration is applied to the proof mass, the overlapping area between the fixed fingers and the moving fingers changes. The change in the capacitances $\mathbf{C}_{\mathbf{1}}, \mathbf{C}_{\mathbf{2}}$ and the difference in capacitance $\mathbf{\Delta} \mathbf{C}$ for a linear displacement of the proof mass in y direction can be obtained by the formula [7]

$$
\begin{aligned}
& C_{1}=\frac{N \varepsilon_{0} L\left(w_{d}+\delta\right)}{2 d} \\
& C_{2}=\frac{N \varepsilon_{0} L\left(w_{d}-\delta\right)}{2 d} \\
& \Delta C=C_{1}-C_{2}
\end{aligned}
$$

where,

$\boldsymbol{\varepsilon}_{\mathbf{0}}$ is the permittivity of free space in $\mathrm{F} / \mathrm{m}$.

$\mathbf{w}_{\mathbf{d}}$ is the width of the overlapping fingers in $\mu \mathrm{m}$.

$\mathbf{L}$ is the length of the overlapping fingers in $\mu \mathrm{m}$.

$\mathbf{d}$ is the distance between the moving fingers and fixed

fingers are in $\mu \mathrm{m}$ and

$\mathbf{N}$ is the number of fixed fingers.

The system exhibits differential capacitances as one side of the capacitance increases and the other side of the capacitance decreases. Capacitance thus obtained for different accelerations is listed in Table 6.

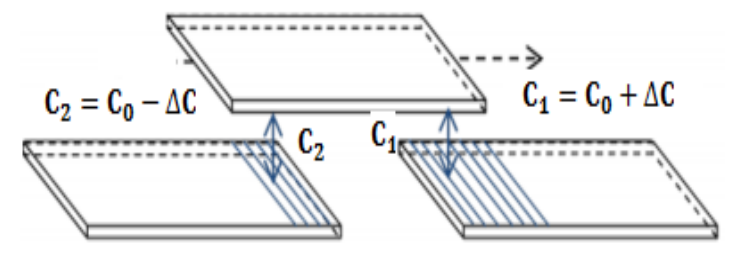

Figure 12. Simplified structure of a differential capacitive sensing.

Table 6. Capacitances obtained at different acceleration.

\begin{tabular}{|c|c|}
\hline Acceleration $\left(\mathbf{m} / \mathbf{s}^{\mathbf{2}}\right)$ & $\begin{array}{c}\text { Theoretical value of } \\
\text { Capacitances } \\
\left(\Delta \mathbf{C}=\mathbf{C}_{\mathbf{1}}-\mathbf{C}_{\mathbf{2}}\right)\end{array}$ \\
\hline 0 & 0 \\
\hline 0.2 & 17.863 \\
\hline 0.4 & 35.735 \\
\hline 0.6 & 53.127 \\
\hline 0.8 & 71.47 \\
\hline 1 & 84.33 \\
\hline 1.2 & 107.25 \\
\hline 1.4 & 123.989 \\
\hline 1.6 & 142.14 \\
\hline 1.8 & 160.784 \\
\hline 2 & 177.074 \\
\hline
\end{tabular}




\section{International Journal of Innovative Research in Electrical, Electronics, Instrumentation and Control Engineering}

Vol. 7, Issue 7, July 2019

A linear increase in capacitance $\mathrm{C}_{1}$ and a linear decrease in capacitance $\mathrm{C}_{2}$ for the given accelerations can be seen in Figure 13.

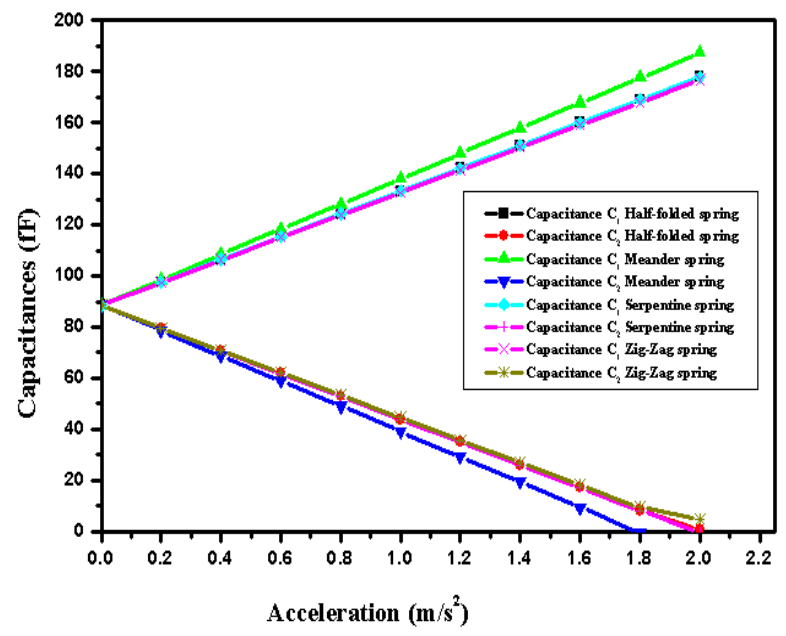

Figure 13. Acceleration Vs Capacitance change for different springs.

\subsection{Output Voltage Analysis}

The capacitances $\mathrm{C}_{1}$ and $\mathrm{C}_{2}$ obtained at various acceleration levels are used to evaluate $\Delta \mathrm{C}$ and $\mathrm{V}_{0}$ subsequently. The output voltage $\mathrm{V}_{0}$ linearly varies with the applied accelerations. $\mathrm{V}_{\mathrm{x}}$ is the input or applied voltage to the proof mass. The $\mathrm{V}_{0}$ was calculated using the formula [12],

$\mathrm{V}_{0}=\frac{\mathrm{C}_{1}-\mathrm{C}_{2}}{\mathrm{C}_{1}+\mathrm{C}_{2}} \quad \mathrm{~V}_{\mathrm{x}}$

\subsection{Non-linearity Analysis}

The percentage non-linearity of the output voltage can be estimated by end point method'

$\% N L=\frac{V_{o i}-V_{o L}}{V_{o L}-V_{o f f}} \times 100$

From the Equation (14), $V_{o i}$ is the preferable output voltage which is obtained from the midpoint. $V_{o L}$ is voltage taken if the output characteristic coincided with the end point[13] as shown in Figure 14.

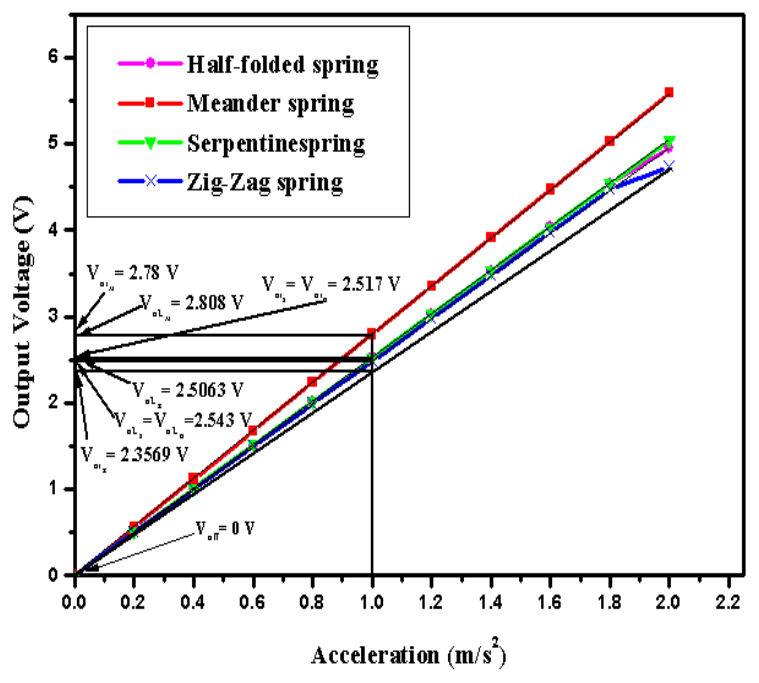

Figure 14. Acceleration Vs Output Voltage. 


\section{International Journal of Innovative Research in Electrical, Electronics, Instrumentation and Control Engineering}

Vol. 7, Issue 7, July 2019

Table 7. Non-linearity analysis of beam springs

\begin{tabular}{|l|c|}
\hline Springs & \% Non-linearity \\
\hline Half-folded & -2.38 \\
\hline Meander & -0.99 \\
\hline Serpentine & -1.022 \\
\hline Zig-Zag & -5.96 \\
\hline
\end{tabular}

\subsection{Frequency Analysis}

The natural frequency of the overlapping area is shown in Table 8. Mode 1 is the natural frequency of the spring in $y$ direction. Mode 2 and Mode 3 are the natural frequency of the spring in $\mathrm{z}$ and $\mathrm{x}$ direction respectively [3]. The natural frequency for 3 modes are given by [14]

$\mathbf{f}=\frac{1}{2 \pi} \sqrt{\frac{\mathbf{k}}{\mathrm{m}}}$

where $\mathbf{k}$ is the spring stiffness in $\mathrm{N} / \mathrm{m}$ and $\mathbf{m}$ is the mass in $\mathrm{kg}$.

Table 8. Three modes of natural frequency $(\mathrm{Hz})$.

\begin{tabular}{|c|c|c|c|c|}
\hline \multirow{2}{*}{ Modes } & \multicolumn{4}{|c|}{ Natural Frequency (Hz) } \\
\cline { 2 - 5 } & $\begin{array}{c}\text { Half-folded } \\
\text { Spring }\end{array}$ & $\begin{array}{c}\text { Meander } \\
\text { Spring }\end{array}$ & $\begin{array}{c}\text { Serpentine } \\
\text { Spring }\end{array}$ & $\begin{array}{c}\text { Zig-Zag } \\
\text { Spring }\end{array}$ \\
\hline Mode 1 & 9.57 & 29.2154 & 31.5361 & 27.2075 \\
\hline Mode 2 & 0 & 62.6869 & 42.5265 & 35.6798 \\
\hline Mode 3 & 194.87 & 195.071 & 195.631 & 195.124 \\
\hline
\end{tabular}

\section{CONCLUSION}

Capacitive accelerometers which are non-linear in nature can be made to produce a linear capacitance measurement by changing the overlapping area between the fixed and moving fingers. Four different beam spring structures are introduced and are subjected to different accelerations. Better cross-axis sensitivity is obtained in Half-folded spring and Serpentine spring compared to the other springs. The capacitive accelerometers with the four spring structures exhibit $<5 \%$ non-linearity. Thus, all the four structures produced linear output and are used to implement in computational and commercial applications like sensors in automobiles and Smart phones.

\section{REFERENCES}

[1]. E. Christy Sujeetha Mary, M.Narayanaswamy, R. Joseph Daniel, "Design and Simulation Studies on Linearised MEMS Capacitive Accelerometer", Proc. IEEE Conference on Emerging Devices and Smart Systems (ICEDSS 2018) 2-3 March 2018, Mahendra Engineering College, Tamilnadu, India, ISBN: 978-1-5386-3479-0/18/2018, pp. 231-234.

[2]. Tse Colin, "Design of a Power Scalable Capacitive MEMS Accelerometer Front End", Master Degree thesis, University of Toronto, 2013.

[3]. Kokcha Payal et al., "Design and Simulation of MEMS Capacitive Accelerometer", International Journal for Technological Research in Engineering, Vol. 2, Issue 12, August 2015.

[4]. Khamil Khairun Nisa BT, “Design and Analysis of MEMS Capacitivity Accelerometer with Optimized Sensitivity”, Master Degree thesis, University of Malaya, 2014.

[5]. Long Nguyen Quang et al., "Capacitive Type Z-axis Accelerometer Fabricated by Silicon-on-insulator Micromachining", Journal of Science \& Technology, No. 95, 2013.

[6]. Li Baoqing et al., "Micro machined accelerometer with area-changed capacitance", Mechatronics 11, pp 811-819, 2001.

[7]. Bedier H and AbdelRassoul Roshdy, "Analysis of Simulation of Serpentine Suspensions for MEMS Applications",International Journal of Materials Science and Engineering, Vol.1, No. 2, December 2013.

[8]. Jaafar Haslina et al., "Design and Simulation of Microelectromechanical System Capacitive Shunt Switches", American J. of Engineering and Applied Sciences, Vol. 2 (4), pp 655-660, 2009.

[9]. Lishchynsk Maryna et al., "Spring Constant Models for Analysis and Design of MEMS Plates on Straight or Meander Tethers", Sensor Letters 4, pp 200-205, 2006.

[10]. Rouabah H. A et al., "Design Optimization of an Electrostatic actuator with Low Spring Constant for an Atom Chip", University of Southampton, NSTI-Nanotech, Vol. 3, 2005

[11]. S, Daniel R Joseph and Sumangala K, "High Performance MEMS accelerometer for concrete SHM applications and comparison with COTS accelerometer", Mechanical systems and Signal Processing, pp 66-67, 2016.

[12]. Lee and Chun Ming, "Design of two-axis capacitive accelerometer using MEMS, Master Degree thesis, Naval Postgraduate School, December 2004

[13]. Sivasundari k et al., "Evolution, modelling and simulation of MEMS PWM pressure sensor employing cantilever switch and SOI diaphragm", Microsyst Technol, Springer-Verlag Berlin Heidelberg 2016

[14]. http://shodhganga.inflibnet.ac.in/bitstream/10603/227 2/8/08_chapter\%202.pdf 